\title{
Süt Endüstrisi Arıtma Çamuru Pirolizinde Sıcaklığın ve Parçacık Boyutunun Sentez Gaz Oluşumuna Etkisi
}

\author{
H. Kurtuluş ÖZCAN ${ }^{*}$, Atakan ÖNGEN ${ }^{1}$, Emine ELMASLAR ÖZBAŞ ${ }^{1}$ \\ ${ }^{1}$ İstanbul Üniversitesi Mühendislik Fakültesi Çevre Mühendisliği Bölümü, İstanbul
}

Geliş tarihi: 02.02.2016 Kabul tarihi: 14.03 .2016

\section{Özet}

Süt endüstrisi atıksu arıtma çamurları genel itibariyle yüksek miktarda organik içeriğe sahiptir. İhtiva ettikleri kalorifik değer bu çamurların alternatif bir enerji kaynağı olarak kullanılabilmelerine olanak sağlamaktadır. Günümüzde faydalanılabilir enerji kaynaklarının kısıtlı olması ve artan enerji ihtiyacını karşılamakta yetersiz kalmasından dolayı alternatif enerji kaynakları için yeni teknolojiler geliştirilmektedir. Piroliz, biyokütleden enerjiyle birlikte katı (biyo çar) sıvı (biyo yağ) gaz (sentez gaz) ürünlerin üretildiği en önemli termokimyasal proseslerden birisidir. Bu çalışmada, süt endüstrisi arıtma çamuru pirolizinde farklı hammadde boyutunun $(<0,5 \mathrm{~cm}, 1-5 \mathrm{~cm}, 5-10 \mathrm{~cm})$ ve sicaklığın $\left(500^{\circ} \mathrm{C}, 750^{\circ} \mathrm{C}\right)$ sentez gaz oluşumuna etkisi incelenmiştir. Çalışmada, en yüksek kalorifik değere sahip sente gaz, 1-5 cm hammadde boyutu ve $750{ }^{\circ} \mathrm{C}$ sıcaklıkta, $4394 \mathrm{kcal} / \mathrm{m}^{3}$ ile elde edilmiştir. Elde edilen sentez gaz miktarları ve 1 sıl değerler, süt endüstrisi atıksu arıtma çamurlarının alternatif bir enerji kaynağı olarak kullanılabileceği öngörüsünü desteklemiştir.

Anahtar Kelimeler: Piroliz, Arıtma çamuru, Atıktan enerji, Sentez gaz

\section{Effect of Temperature and Particle Size on Diary Industry Treatment Sludge Pyrolysis}

\begin{abstract}
Dairy industry wastewater treatment sludge consists of high organic content. The calorific value of wastewater treatment sludge ensures the use of these wastes as an alternative energy resource. New technologies and alternative energy resources have been researched due to ever-increasing need for

\footnotetext{
* Yazışmaların yapılacağı yazar: H. Kurtuluş ÖZCAN, İstanbul Üniversitesi Mühendislik Fakültesi, Çevre Mühendisliği Bölümü, Istanbul.hkozcan@istanbul.edu.tr
} 
energy and limited available energy resources in the world. Pyrolysis is one of the thermochemical technologies for converting biomass into energy and chemical products consisting of liquid bio-oil, solid biochar, and syngas. This study investigated the change in synthesis gas compounds obtained from the pyrolysis of dairy industry wastewater sludge according to the temperature $\left(500^{\circ} \mathrm{C}, 750^{\circ} \mathrm{C}\right)$ different particle size $(<0,5 \mathrm{~cm}, 1-5 \mathrm{~cm}, 5-10 \mathrm{~cm})$. The highest calorific value of synthesis gas obtained from the tests was calculated as $4394 \mathrm{kcal} / \mathrm{m}^{3}$ with $1-5 \mathrm{~cm}$ particle size and at $750^{\circ} \mathrm{C}$. Synthesis gas concentration and calorific values obtained from dairy industry waste water sludge supported that this waste could be used as an alternative energy resource.

Keywords: Pyrolysis, Treatment sludge, Waste-to-energy, Syngas

\section{GİRIŞ}

Piroliz, bir diğer adıyla karbonizasyon, oksijen yokluğunda organik materyallerin 1sı ile kimyasal bozunması olarak tanımlanmaktadır. Bilinen en yaygın piroliz prosesi odun kömürü üretimidir. Pratikte, tamamen oksijensiz ortam sağlayabilmek mümkün olamayacağından pirolitik sistemler temelde stokiyometrik olarak belirlenen oksijen miktarından daha az miktarda oksijenle yürütülmektedir. $\mathrm{Bu}$ bağlamda, yakma ve piroliz arasında 2 temel farklılık bulunmaktadır. Birincisi, yanma reaksiyonları 1Sı açığa çıkaran (ekzotermik) süreçlerken, piroliz 1sıya ihtiyaç duyan (endotermik) süreçtir. İkinci farklılık ise, yanma ürünleri olarak $\mathrm{CO}_{2}$, su ve kül elde edilirken piroliz sonucunda katran, yağ, zift ve yakıt gaz eldesi mümkündür [1,2].

Piroliz sonucu elde edilen katı ürünler çar, kül ve biyoyakıttır. Char genellikle piroliz katı ürünlerinin en önemlisidir. Piroliz sonucu elde edilen ürünlerin kimyasal kompozisyonunu piroliz şartları belirlemektedir. Genellikle pirolizde sıcaklığın artmasıyla katı ürün oluşumu azalmaktadır. Katı ürünler 1 sı ve elektrik üretiminde, gazlaştırma işlemleri için hammadde olarak kullanılabilir. Ayrıca, piroliz işlemi ile üretilen katı ürünler aktifleştirilip aktif karbona dönüştürülmektedir [3]. Piroliz sonrası elde edilen bu yan ürünler yanma işlemi için yakıt olarak kullanılabilmektedirler. Ayrica, piroliz ile elde edilen yakıt ürünlerde, yanma ürünlerinde gözlenen sülfür gibi kirleticilerin ihtivası daha düşüktür [4]. Piroliz yararlı enerji (yakıt) ve kimyasal maddelerin üretimi için bağımsız bir işlem olarak da kullanılabilir. Piroliz, kömür, biyokütle gibi hammaddelere uygulanabileceği gibi, farklı kaynaklardan gelen ve çok değişken miktarlarda ve özelliklerdeki katı atıklar için de uygulanabilecek bir enerji dönüşüm sürecidir [5-7].

Piroliz yöntemleri; 1sıtma hızı, biyokütlenin alıkonma süresi ve sıcaklık gibi işlem koşullara bağlı olarak ayrılır. Piroliz işlemi genel olarak üç farklı şekilde yürütülür. Bunlar; yavaş piroliz (geleneksel), flaş piroliz ve hızlı pirolizdir. Her piroliz işlemi sonucunda katı, sıvı ve gaz ürün çıkar ama çıkan ürün oranı olarak bir birinden farklılık göstermektedir [8,9]. Piroliz sıcaklığı başta olmak üzere 1sıtma hızı, basınç, parçacık boyutu, piroliz ortamı, katalizör, reaktör geometrisi ve reaksiyon süresi piroliz verimlerini etkileyen parametrelerdir [10]. Sicaklık piroliz işlemini hem ürün verimi hem de ürün bileşimi açısından etkileyen en önemli faktördür. Sicaklık ile elde edilen ürün arasında yakın bir ilişki vardır. İşlemin sıcaklık düzeyi arttıkça sıvı ve gaz ürün daha fazla elde edilirken, katı ürün oranında azalma görülür. Piroliz işlemi, sıcaklık değerlerine göre üç safha olarak değerlendirilebilir; birinci safha $100-300^{\circ} \mathrm{C}$ sıcaklık uygulandığı safhadır ve katı ürünler daha fazla elde edilir. İkinci safha ise $500^{\circ} \mathrm{C}$ 'ye kadar sıcaklık uygulandığı aşamadır bu seviyede elde edilen sıvı ürünlerin miktarı artmaktadır. Üçüncü safha ise $700^{\circ} \mathrm{C}$ 'den yüksek piroliz sıcaklığına ulaşılır ve bu safhadan sonra gaz şeklinde çoğunlukla $\mathrm{H}_{2}, \mathrm{CO}$ ve $\mathrm{CH}_{4}$ elde edilir [11].

Arıtma çamurları atıksuların yapısında bulunan, kendiliğinden çökebilen maddelerin atık sudan 
ayrılması veya çeşitli arıtma prosesleri sonucu ortaya çıkan çökelen/yüzdürülen katı maddeleri ifade etmektedir. Arıtma çamurları kaynaklandığı atıksulara bağlı olarak çok farklı fizikokimyasal özelliklerde olabilirler [12]. Arıtma çamurlarının yönetimi ve değerlendirilebilirliği bir çok çalışmacının ilgisini çekmektedir. Evsel atıksu çamurları ya da süt endüstrisi gibi organik madde içeriği yüksek endüstrilerden kaynaklanan arıtma çamurları klasik berteraf yöntemlerine nazaran farklı şekillerde değerlendirilebilmektedir. Günümüzde entegre süt ve süt ürünleri tesislerinin sayısı artmış ve bunun sonucu olarak da bu sanayiden kaynaklanan atıksu miktarı artmıştır. Süt endüstrisi atıksuları yüksek oranda biyolojik parçalanabilir özelliğe sahiptirler ve fizikselkimyasal, biyolojik metotlar ile arıtılabilmektedir. Aerobik prosesler, özellikle de aktif çamur tesisleri, süt endüstrisi atıksularının arıtımında sıkça kullanılmaktadır [13]. $\mathrm{Bu}$ nedenle bu tesislere ait arıtma çamurları yüksek oranda $\mathrm{C}$ ve $\mathrm{H}$ içeriğine sahip olmaktadırlar. Bu özelliklerinden dolayı bu materyallerin termal yollarla berterafi avantajlı olmaktadır [14]. Modern atık yönetimi prensiplerinde atıkların geri kazanımı ve enerji eldesi öncelikli olmaktadır. Bu bağlamda süt endüstrisi atıksu arıtma çamurları gibi yüksek organik madde içeriğine sahip atıksulardan enerji eldesi modern atık yönetim sisteminin bir parçasıdır.

$\mathrm{Bu}$ çalışmada, süt endüstrisi atıksu arıtma tesisi çamurlarının sabit yataklı reaktörde piroliz yöntemiyle değerlendirilebilirliği araştırılmıştır. $\mathrm{Bu}$ amaçla farklı sıcaklık ve numune boyutları denenerek bu parametrelerin oluşan sentez gaz kompozisyonuna etkisi incelenmiştir.

\section{2. ÖNCEKİ ÇALIŞMALAR}

Literatür incelendiğinde, piroliz ve gazlaştırma gibi termokimyasal yöntemlerin atık yönetiminde sıkça kullanıldığı görülmektedir. Bu işlemler daha çok kömürün gazlaştırılması için kullanılsa da, farklı atık türlerinin pirolizine ve gazlaştırılmasına dair bir çok çalışma bulunmaktadır [15-17]. Arıtma çamurları içerdiği yüksek oranda karbonlu bileşikler dolayısıyla piroliz işlemine uygun atıklardır. $\mathrm{Bu}$ nedenle bir çok araştırmacı hem evsel nitelikli arıtma çamurlarının hem de çeşitli endüstrilerden kaynaklanan çamurların termokimyasal berterafinı çalışmışlardır. Han ve arkadaşları [18] çalışmalarında evsel nitelikli arıtma çamurlarının pirolizinde sentez gaz oluşumunu incelemişlerdir. Farklı sıcaklıklar için $\left(500^{\circ} \mathrm{C}, \quad 700^{\circ} \mathrm{C}\right.$ ve $\left.900^{\circ} \mathrm{C}\right)$, sentez gaz kompozisyonunda $\mathrm{H}_{2}, \mathrm{CO}, \mathrm{CH}_{4}$ ve $\mathrm{CO}_{2}$ bileşenlerinin hacimsel yüzdelerini ölçmüşlerdir. Ayrıca pirolizden elde edilen sentez gazın kalorifik değerini de belirlemişlerdir. Çalışmada $\mathrm{H}_{2}$ ve $\mathrm{CH}_{4}$ açısından zengin sentez gazın $700^{\circ} \mathrm{C}$ üzerinde elde edildiğini bulmuşlardır.

Liu ve arkadaşları [19] endüstriyel kaynaklı arıtma çamurlarının pirolizini incelemişlerdir. Çalışmada kimya ve kereste endüstrisinden temin edilen arıtma çamurları kullanılmıştır. Bu çalışmada elde edilen bulgulara göre piroliz prosesinde materyallerin temel bozunma aralığ $200^{\circ} \mathrm{C}$ ile $600^{\circ} \mathrm{C}$ arasında olmaktadır. Ayrica piroliz prosesi ile yaklaşık olarak \%40 oranında hacimsel atık azaltımı olduğu belirtilmiştir.

Yuan ve arkadaşları [20] çalışmalarında, evsel nitelikli arıtma çamurlarından elde edilen biochar maddesinin karakterizasyonunu yapmış ve bu maddenin tarımsal uygulamalardaki kullanılabilirliğini incelemişlerdir. Çalışmada $300^{\circ} \mathrm{C}$ ile $700^{\circ} \mathrm{C}$ arasında değișen sicaklıklarda piroliz işlemi uygulanmıştır. Piroliz reaksiyonlarında oksijensiz ortamı sağlamak adına $1 \mathrm{~L} / \mathrm{dk}$ akış hızında azot gazı kullanmışlar ve biochar oluşumunun artan sicaklığa bağlı olarak azaldığını ortaya koymuşlardır.

\section{MATERYAL VE METOT}

\subsection{Deneysel Yöntem}

$\mathrm{Bu}$ çalışmada süt endüstrisine ait susuzlaştırılmış atıksu arıtma çamuru numunesi kullanılmıştır. Çamur numuneleri $<0,5 \mathrm{~cm} ; 1-5 \mathrm{~cm} ; 5-10 \mathrm{~cm}$ şeklinde 3 boyutta ayrılmış, ve her birine 500 ve $750^{\circ} \mathrm{C}$ 'de piroliz işlemi uygulanmıştır. Piroliz deneyleri 2 L hacimli sabit yataklı çelik reaktörde gerçekleştirilmiştir. Reaktör, yardımcı olarak 
kullanılan gazların (kuru hava, azot vb.) girișine imkan verecek iki adet gaz giriși hattına ve üretilen gazın çıkmasına olanak sağlayan bir adet çıkış hattına sahiptir. Reaktör ağzından gaz kaçağı olmasını engellemek için saf grafit veya grafitkurşun sarmal contalar kullanılmıştır (Şekil 1). Piroliz deneylerinde sürükleyici gaz olarak $\mathrm{N}_{2}$ kullanılmıştır.

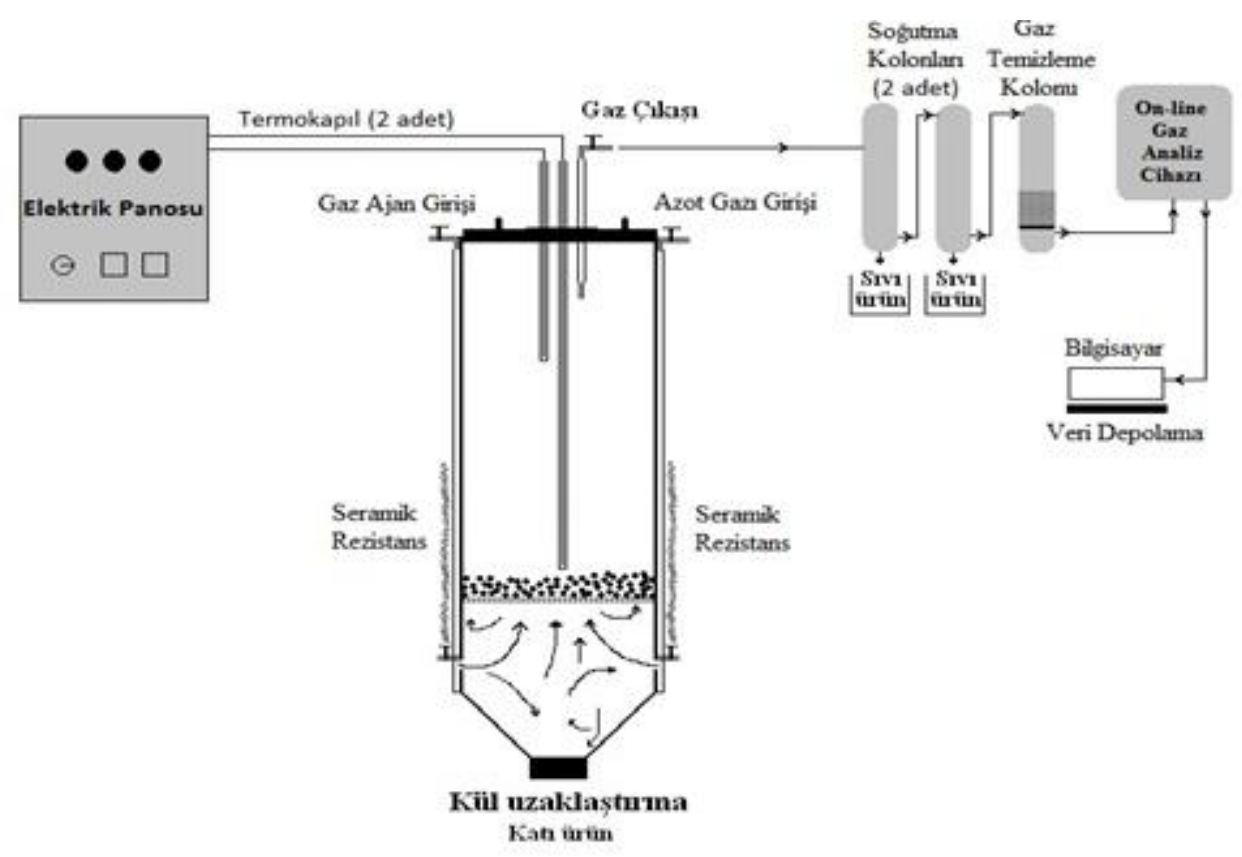

Şekil 1. Piroliz reaktörü ve analiz sisteminin şematik gösterimi

\subsection{Analitik Yöntem}

Piroliz süresince oluşan gazın içerisindeki $\mathrm{CO}$, $\mathrm{CO}_{2}, \mathrm{H}_{2}, \mathrm{CH}_{4}$, ve $\mathrm{O}_{2}$ miktarları hacimsel yüzde olarak ölçülmüştür. Sentetik gaz ölçümleri için ABB marka AO2020 model sürekli gaz analizörü kullanılmışır. $\mathrm{Bu}$ analizler sonucunda elde edilen ölçüm değerleri gaz analiz cihazından veri aktarım kablosu aracılığıyla bilgisayara aktarılmış ve kaydedilmiştir. Elementel analiz deneylerinde, Truspec CHN-S elementel analiz cihazı kullanılmıştır. Deneysel çalışmalarda kullanılan arıtma çamuru örneklerinin fiziksel ve kimyasal bazı özelliklerini belirlemek için, nem içeriği, kül içeriği, yanma kaybı ve katı madde içeriği deneyleri standard metotlara göre yürütülmüştür $[21,22]$.

Çalışmalar sonucunda elde edilen sentez gazların 1s1 değerlerinin hesaplanması için gaz kompozisyonu içerisinde bulunan $\mathrm{CO}, \mathrm{H}_{2}$ ve
$\mathrm{CH}_{4}{ }^{\prime} \mathrm{e}$ ait üst ${ }_{1 s 1}$ değerlerinin bilinmesi gerekmektedir. Isıl değer hesaplamaları Çizelge 1'de verilen 1sıl değerlerin yardımıyla matematiksel olarak hesaplanmıştır [23].

Çizelge 1. Bazı gazların üst 1sıl değeri

\begin{tabular}{|c|c|c|c|}
\hline Gazlar & $\begin{array}{c}\text { Yoğunluk } \\
\left(\mathrm{kg} / \mathrm{m}^{3}\right)\end{array}$ & $\mathrm{MJ} / \mathrm{m}^{3}$ & $\mathrm{kcal} / \mathrm{m}^{3}$ \\
\hline $\mathrm{CO}$ & 1,25 & 12,64 & 3020 \\
\hline $\mathrm{CH}_{4}$ & 0,71 & 39,82 & 9520 \\
\hline $\mathrm{H}_{2}$ & 0,08 & 12,77 & 3050 \\
\hline
\end{tabular}

\section{BULGULAR VE TARTIŞMA}

Çalışmanın birinci kısmında, deneylerde kullanılacak süt endüstrisi atıksu arıtma çamurunun bazı fiziksel ve kimyasal özellikleri belirlenmeye çalışılmıştır. $\mathrm{Bu}$ amaçla elementel analiz, nem oranı, kül miktarı, yanma kaybı, ve 
katı madde miktarı belirlenmiștir. $\mathrm{Bu}$ deneylerden elde edilen sonuçlar Çizelge 2'de sunulmuştur. Birçok biyokütle kaynağı piroliz ve gazlaştırma gibi termokimyasal proseslere uygun olmasına rağmen, ideal olarak hammaddenin nem içeriği \%5-35 aralığında olması istenir. Çizelge 2 incelendiğinde; arıtma çamuru örneklerinin nem içeriğinin \%19,85 olduğu görülmektedir. Ayrıca \%79,5 kül içeriğine sahip olması örneklerin yüksek miktarda organik içeriğe sahip olduğunun bir göstergesidir. Kalorifik değeri yüksek sentez gaz, daha çok karbon ve hidrojen içeriğe sahip yakıtlardan elde edilmektedir. $\mathrm{Bu}$ nedenle, prioliz denemelerine başlamadan önce ham arıtma çamurunu numunesinin elementel analizi yapılmıştır. Analiz sonucunda numunenin $\% 47,87$ karbon ve $\% 8,19$ hidrojen içerdiği tespit edilmiştir (Çizelge 2). Bu değerler süt endüstrisi arıtma çamuru örneklerinin piroliz yöntemi için uygun bir hammadde olduğunun bir diğer göstergesidir. Parçacık boyutunun piroliz işlemine etkisini belirleyebilmek adına, üç farklı boyutta ve iki farklı sıcaklıkta deneyler yürütülmüştür. $500^{\circ} \mathrm{C}$ sicaklıkta, $<0,5 \mathrm{~cm}, 1-5 \mathrm{~cm}$ ve $5-10 \mathrm{~cm}$ boyutlu örnekler için elde edilen sentez gaz kompozisyonun zamansal değişimleri Şekil 2, Şekil 3 ve Şekil 4'de sunulmuştur.

Çizelge 2. Ham arıtma çamurunun fiziko-kimyasal özellikleri

\begin{tabular}{|c|c|c|c|c|}
\hline \multicolumn{5}{|c|}{ Kimyasal Analiz, \% ağırlık } \\
\hline Nem & Kül & Yanma Kaybı & \multicolumn{2}{|c|}{ Katı Madde } \\
\hline 19,85 & 79,5 & 20,4 & \multicolumn{2}{|c|}{95,3} \\
\hline \multicolumn{2}{|l|}{ Elementel Analiz, \% } & & \multirow{2}{*}{\multicolumn{2}{|c|}{$\mathrm{N}$}} \\
\hline & $\mathrm{C}$ & $\mathrm{H}$ & & \\
\hline & 47,87 & 8,19 & 3,99 & - \\
\hline
\end{tabular}

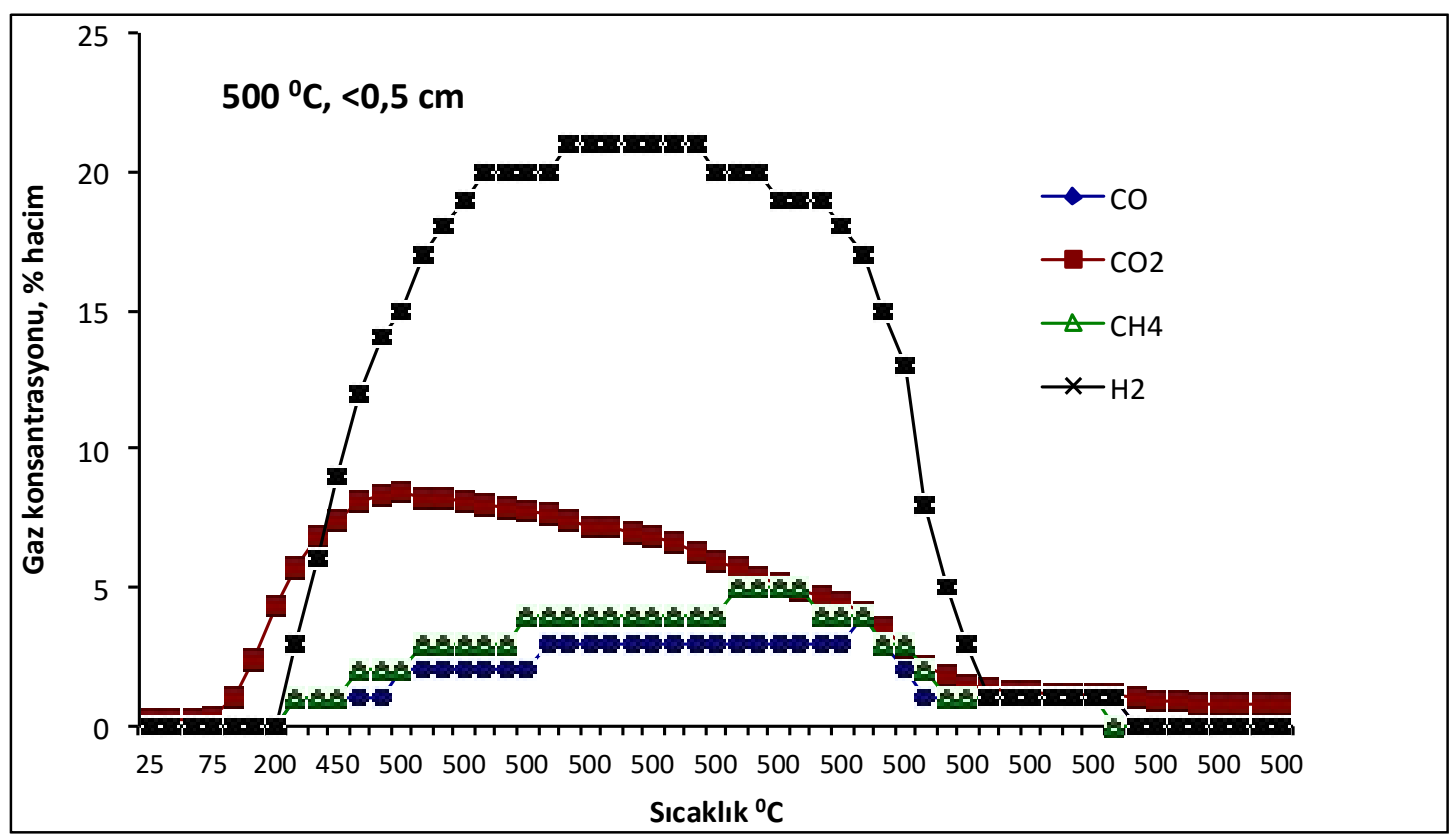

Şekil 2. $500^{\circ} \mathrm{C}$ piroliz işlemine ait sentez gaz analiz sonuçları (Tanecik boyutu $<0,5 \mathrm{~cm}$ ) 
Şekil 2 ve Şekil 3 incelendiğinde; arıtma çamuru örneklerinin termal bozunumunda $<0,5$ ve $1-5 \mathrm{~cm}$ örnekleri için benzer gaz kompozisyonunun oluştuğu görülmektedir. Her iki parçacık boyutu için $250-300^{\circ} \mathrm{C}$ civarında sentez gaz oluşumu gözlemlenmeye başlamış ve $500^{\circ} \mathrm{C}$ sıcaklığa ulaşıldığında sentez gaz bileşenleri maksimum seviyelerine ulaşmıştır. $<0,5$ boyutunda, $\mathrm{H}_{2}$ yüzdesi, $\quad 450-500^{\circ} \mathrm{C}$ sicaklıkları arasında
\%19-21 ile maksimum değerine ulaşırken, aynı sıcaklık aralığında, isıl değer açısından önem taşıyan $\mathrm{CH}_{4}$ ve $\mathrm{CO}$ gazlarının yüzdeleri sırasıyla $\% 5$ ve $\% 3$ olarak tespit edilmiştir. $1-5 \mathrm{~cm}$ örnekleri için elde edilen $\mathrm{H}_{2}$ değerlerinin en yüksek seviyesi \%26 olarak ölçülmüştür (Şekil 3).

$\mathrm{CH}_{4}$ ve $\mathrm{CO}$ ise $<0,5$ örnekleri ile benzer şekilde sırasıyla $\% 5$ ve $\% 3$ olarak ölçülmüştür.

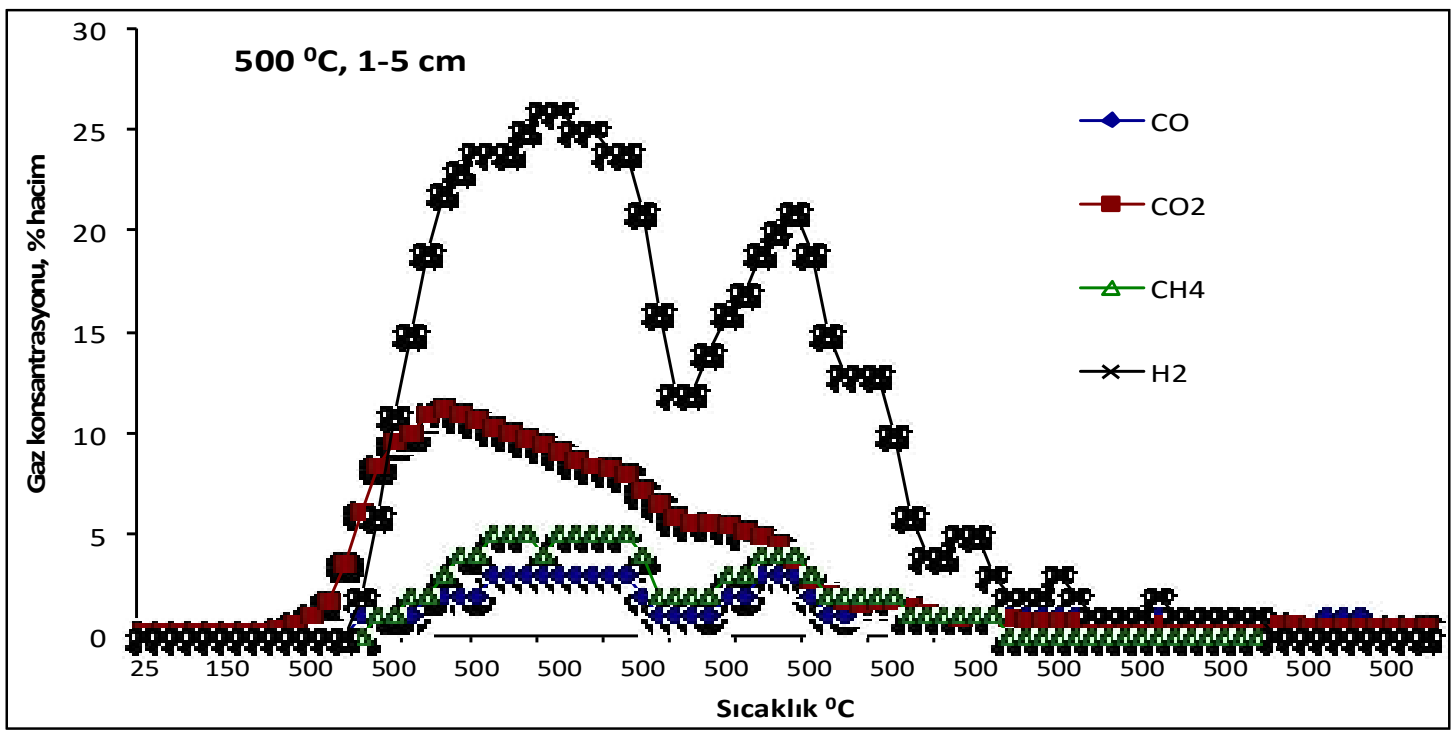

Şekil 3. $500^{\circ} \mathrm{C}$ piroliz işlemine ait sentez gaz analiz sonuçları (tanecik boyutu $1-5 \mathrm{~cm}$ )

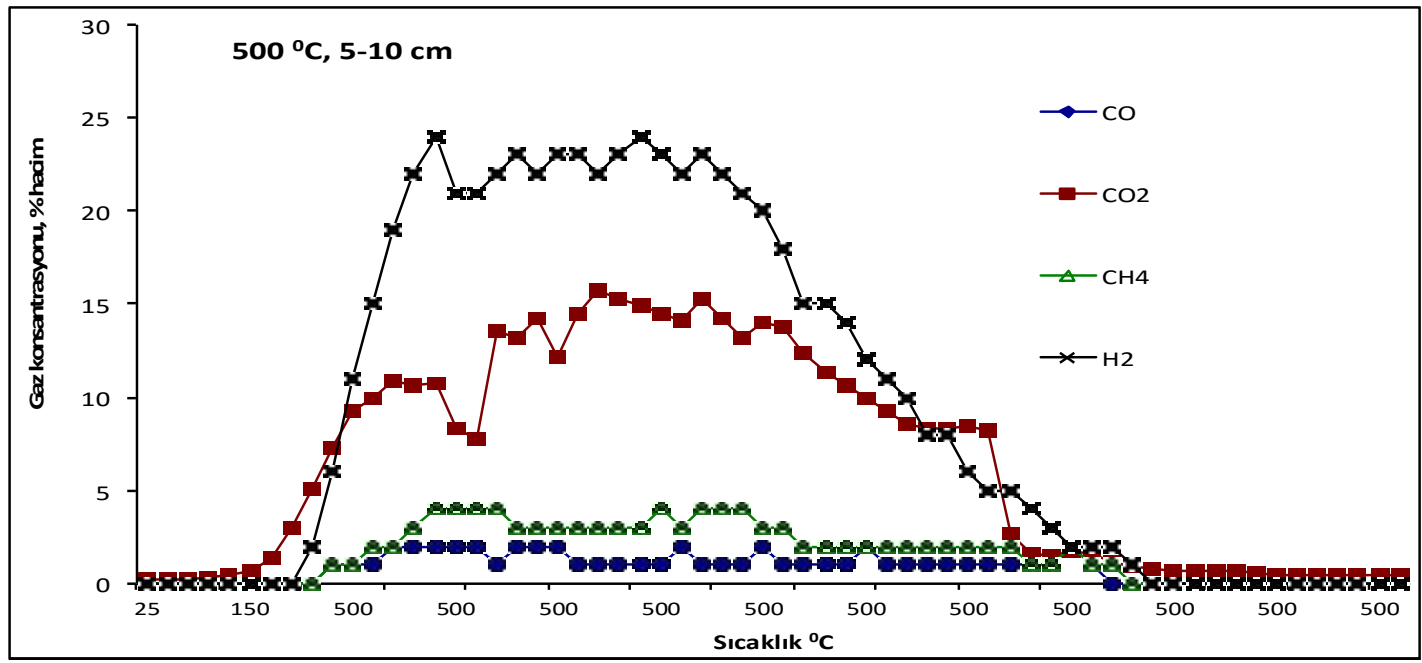

Şekil 4. $500^{\circ} \mathrm{C}$ piroliz işlemine ait sentez gaz analiz sonuçları (tanecik boyutu $5-10 \mathrm{~cm}$ ) 
$5-10 \mathrm{~cm}$ boyutlu örneklerin pirolizinden elde dilen sentez gaz bileşimi incelendiğinde, diğer iki parçacık boyutundan farklı olarak $\mathrm{H}_{2}$ değerlerinin bir miktar arttığı görülmektedir (Şekil 4). $\mathrm{H}_{2}$ değerinin en yüksek seviyesi bu deneyde \%24 olarak ölçülmüştür. $\mathrm{CH}_{4}$, bu denemede $\% 4$ olarak tespit $\mathrm{CO}$ ise, $\% 2$ olarak ölçülmüştür. $\mathrm{Bu}$ verilerin 1şı ğında, $500^{\circ} \mathrm{C}$ de yapılan piroliz deneylerinde parçacık boyutunun değişiminin sentez gaz kompozisyonunu etkilediği anlaşılmaktadır. Sentez gazın $\mathrm{CH}_{4}, \mathrm{H}_{2}$ ve $\mathrm{CO}$ bileşenlerinin yüksek olması doğal olarak isıl değeri arttırmaktadır. $\mathrm{Bu}$ doğrultuda, $500^{\circ} \mathrm{C}$ pirolizlerde elde edilen sentez gazın en yüksek 1sıl değeri, $1359 \mathrm{kcal} / \mathrm{m}^{3}$ ile 1-5 cm parçacık boyutunda hesaplanmıştır. Diğer 1sıl değerler ise $5-10 \mathrm{~cm}$ parçacık boyutu için $1173,2 \mathrm{kcal} / \mathrm{m}^{3}, \quad<0,5$ parçacık boyutu için $1176 \mathrm{kcal} / \mathrm{m}^{3}$ olarak bulunmuştur. En yüksek 1sıl değer, $\quad 450-500^{\circ} \mathrm{C}$ sicaklık aralığında elde edilmiştir. Sicaklığın piroliz ürünlerine olan etkisini incelemek amacıyla aynı parçacık boyutları için $750^{\circ} \mathrm{C}$ 'de denemeler yapılmıştır. $\mathrm{Bu}$ denemelere ait sentez gazların sicaklığa bağlı değişimi Şekil 5, Şekil 6 ve Şekil 7'de sunulmuştur. $500^{\circ} \mathrm{C}$ 'de yapılan pirolizlere benzer oarak, bu deneylerde de $250^{\circ} \mathrm{C}$ civarında numunenin bozunmaya başladığı belirlenmiş, özellikle $500^{\circ} \mathrm{C}$ ve üzerindeki sıcaklıklarda sentez gaz miktarlarının giderek arttığı ve $700-750^{\circ} \mathrm{C}$ aralığında maksimum mertebelere ulaştığı gözlenmiştir. Şekil 5 incelendiğinde $<0,5 \mathrm{~cm}$ parçacık boyutu için $\mathrm{H}_{2}$ gazının oluşumunun $300^{\circ} \mathrm{C}$ den sonra hizla arttı̆̆ 1 ve $750^{\circ} \mathrm{C}$ 'de $\% 45$ ile maksimum seviyesine ulaştığı görülmektedir. $\mathrm{CH}_{4}$ ve CO gazları da benzer bir artışla $750^{\circ} \mathrm{C}$ 'de en yüksek değerlerine ulaşmışlardır. $\mathrm{CH}_{4}$ ve $\mathrm{CO}$ gazlarının bu deneylerde ölçülen en yüksek değerleri sırasıyla \%23 ve \%28'dir. Şekil 6 ve Şekil 7'de sunulan $1-5 \mathrm{~cm}$ ve $5-10 \mathrm{~cm}$ parçacık boyutlarından elde edilen sentez gaz bileşimi de $<0,5$ parçacık boyutundan elde edilen gaz bileşiminyle benzerlik göstermektedir. $\mathrm{H}_{2}, \mathrm{CH}_{4}$ ve $\mathrm{CO}$ kompozisyonları incelendiğinde bütün parçacık boyutları için $\mathrm{H}_{2}$ 'nin en yüksek değeri $\% 45$ olarak hesaplanmıştır. 1-5 cm parçacık boyutu için, $\mathrm{CH}_{4}$ ve $\mathrm{CO}$ gazlarının maksimum yüzdeleri sırasıyla $\% 27$ ve $\% 25,5-10 \mathrm{~cm}$ için $\% 23$ ve $\% 37$ olarak olarak tespit edilmiştir.

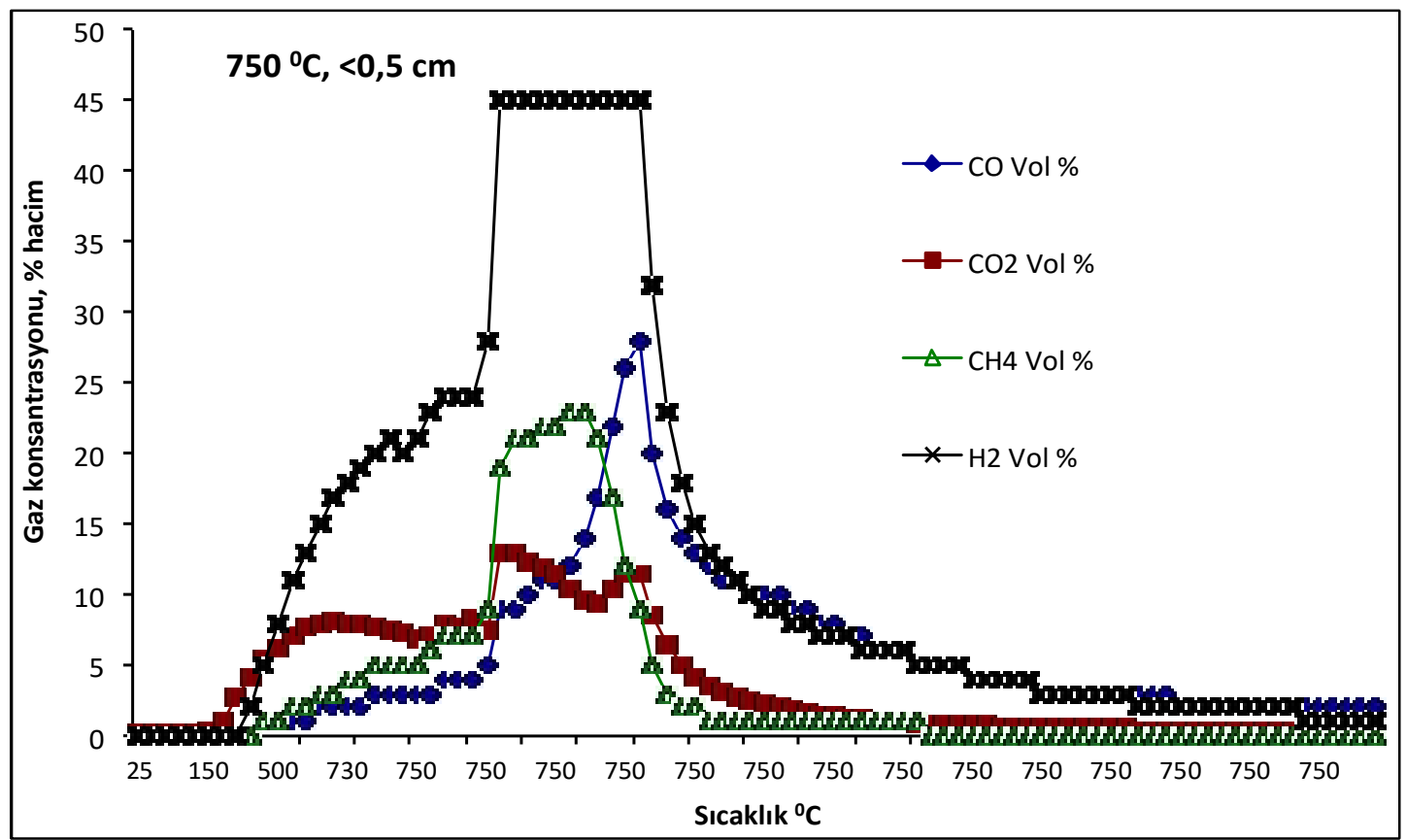

Şekil 5. $750^{\circ} \mathrm{C}$ piroliz işlemine ait sentez gaz analiz sonuçları (Tanecik boyutu $<5 \mathrm{~cm}$ ) 


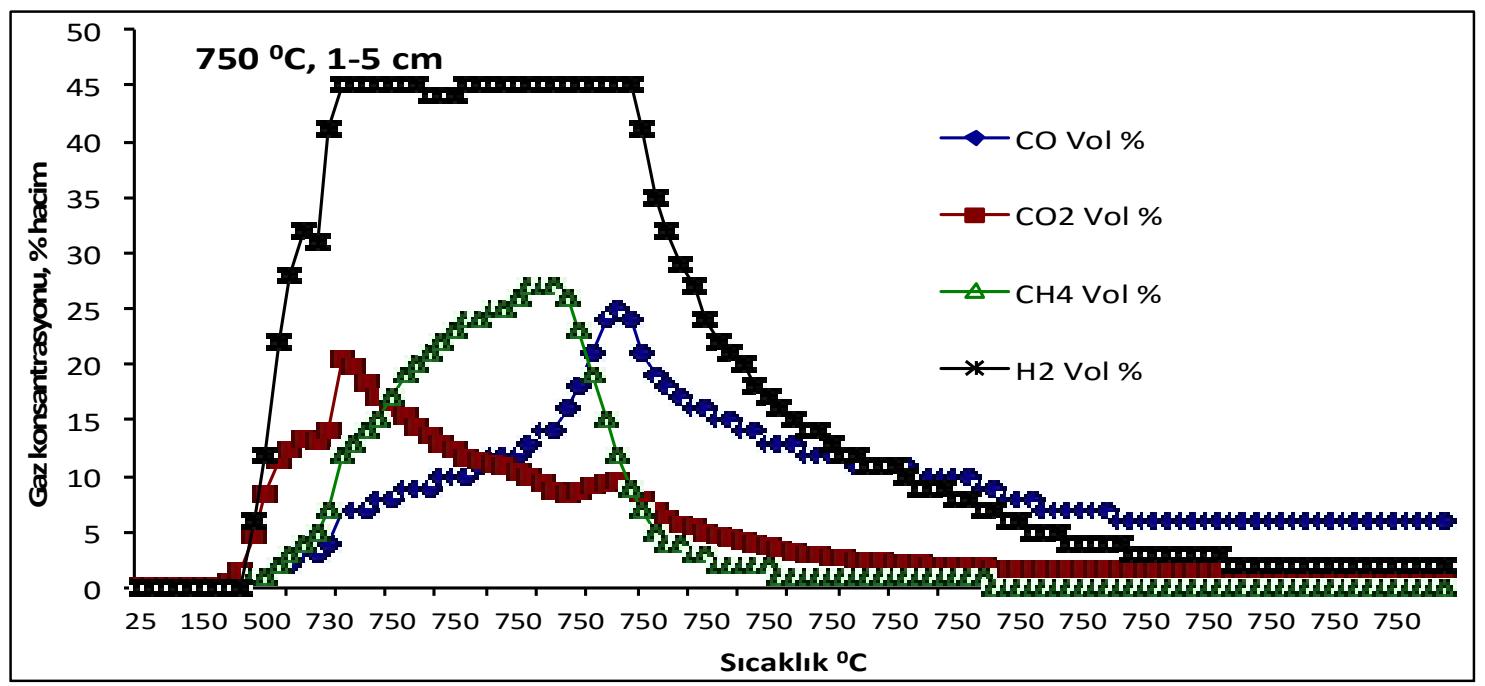

Şekil 6. $750^{\circ} \mathrm{C}$ piroliz işlemine ait sentez gaz analiz sonuçları (Tanecik boyutu $1-5 \mathrm{~cm}$ )

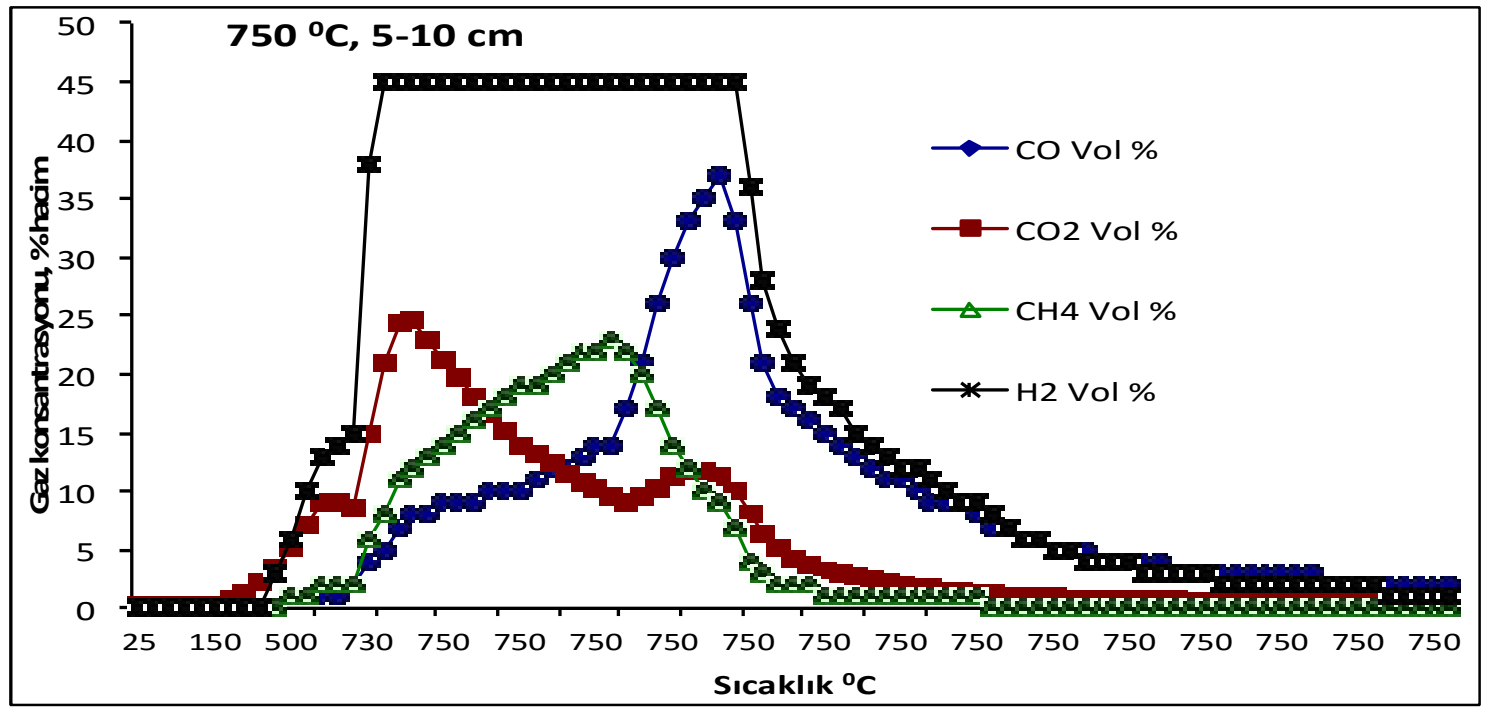

Şekil 7. $750^{\circ} \mathrm{C}$ piroliz işlemine ait sentez gaz analiz sonuçları (Tanecik boyutu $5-10 \mathrm{~cm}$ )

$750^{\circ} \mathrm{C}$ 'de yapılan pirolizden elde edilen sentez gazların 1sıl değerler incelendiğinde, bütün parçacık boyutları için $4000 \mathrm{kcal} / \mathrm{m}^{3}$ civarında olduğu görülmektedir. $500^{\circ} \mathrm{C}$ ile kıyaslandığında bu değerler oldukça yüksektir. $750^{\circ} \mathrm{C}$ 'de ulaşılan en yüksek isıl değerler $<0,5 \mathrm{~cm}$ boyutunda $4014 \mathrm{kcal} / \mathrm{m}^{3}, 1-5 \mathrm{~cm}$ için $4394 \mathrm{kcal} / \mathrm{m}^{3}$ ve $5-10$ için $4016 \mathrm{kcal} / \mathrm{m}^{3}$ olarak hesaplanmıştır. Çalışma süresince yürütülen tüm denemeler sonucunda elde edilen gaz formlarının yüzdelerini kullanarak her deneme için 1sıl değerler hesaplanmış Şekil 8'de gösterilmiştir. Deneylerde 20 ve 35 . dakikalar arasında reaksiyonların olgunlaştığı ve örneğin uçucu kısmının önemli oranının reaktörden uzaklaştı̆̆ı gözlenmiştir. Isıl değerler incelendiğinde $750^{\circ} \mathrm{C}$ 'de maksimum isıl değerlere ulaşıldığ 1 tespit edilmiştir. Hesaplanan 1sıl değerlere göre sistemden en yüksek verimin $750^{\circ} \mathrm{C}$ de $1-5 \mathrm{~cm}$ boyutunda taneciklerle alındığ 1 tespit edilmiştir. $750^{\circ} \mathrm{C}$ de $<0,5 \mathrm{~cm}$ boyutundaki 
taneciklerle 5-10 $\mathrm{cm}$ boyutundaki taneciklerde 1sil değerlerin birbirine yakın seviyelerde olduğu hesaplanmıştır. $\quad 500^{\circ} \mathrm{C}$ 'de yürütülen piroliz deneylerinde parçacık boyutunun artmasının deney sonrasında elde edilen katı kalıntı miktarını arttırdığı ve sentez gaz verimini düşürdüğü görülmektedir (Çizelge 3). Söz konusu sicaklıklarda yürütülen piroliz deneylerinde en az katı kalıntı ve en yüksek sentez gaz verimine $1-5 \mathrm{~cm}$ parçacık boyutunda ulaşılmıştır. $750^{\circ} \mathrm{C}$ 'de yürütülen deneyler incelendiğinde, parçacık boyutunun elde edilen sentez gaz ve diğer ürünleri (sıvı, katı) çok fazla etkilemediği görülmektedir (Çizelge 3). $750^{\circ} \mathrm{C}$ sıcaklık için $500^{\circ} \mathrm{C}$ 'ye nazaran daha az katı ve daha fazla gaz ürün elde edilmiştir. $\mathrm{Bu}$ durum artan sicaklikla birlikte organik maddenin daha yüksek oranda sistemden uzaklaştığının ve sıcaklığın parçacık boyutuna nazaran sentez gaz ve diğer ürünlerin oluşumuna daha etkili olduğunun bir göstergesidir.

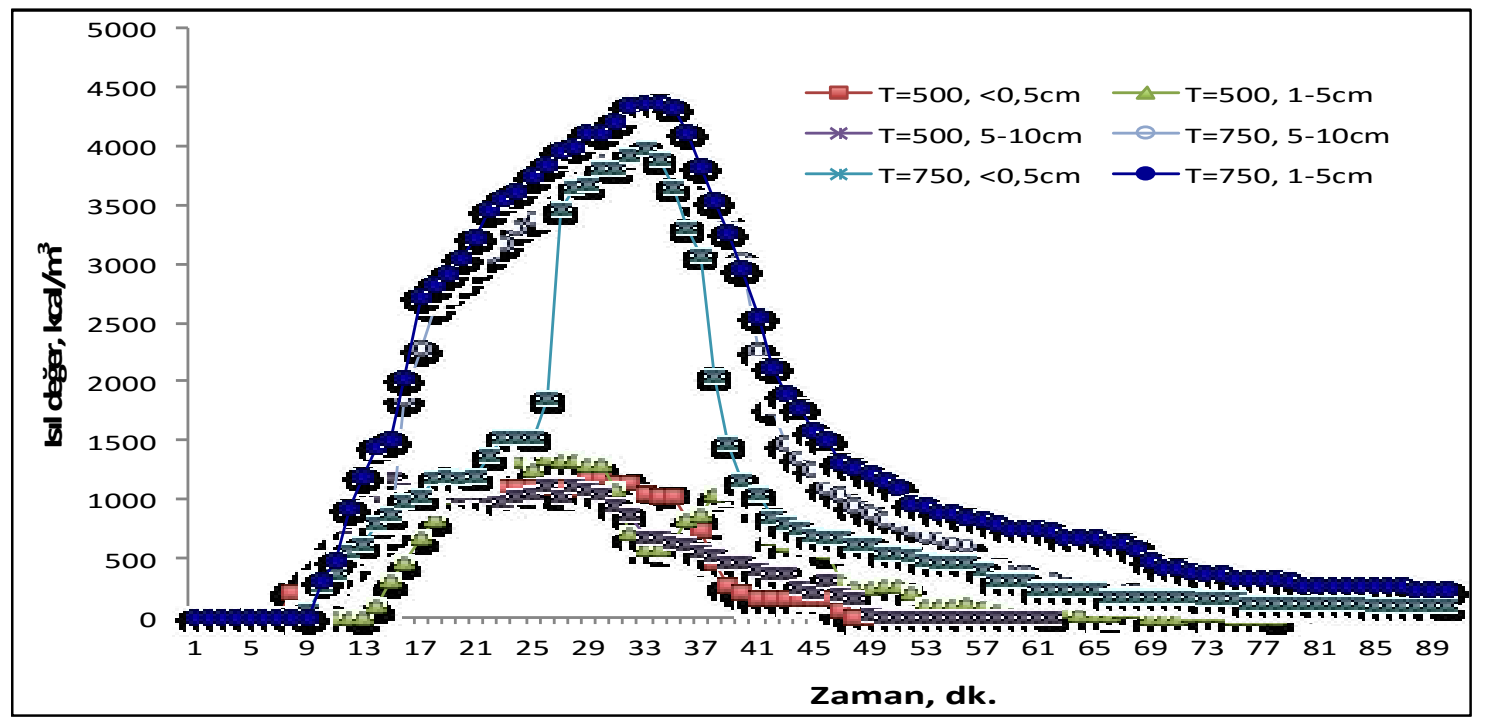

Şekil 8. Piroliz süresine bağlı olarak 1sıl değerlerin değişimi

Çizelge 3. Piroliz deneyleri sonucunda elde edilen sıvı ve katı ürün miktarı

\begin{tabular}{|l|c|c|c|c|}
\hline Piroliz Şartları & $\begin{array}{c}\text { Hammadde } \\
(\mathrm{g})\end{array}$ & $\begin{array}{c}\text { S1v1 Ürün } \\
(\mathrm{g})\end{array}$ & $\begin{array}{c}\text { Kat1 Ürün } \\
(\mathrm{g})\end{array}$ & $\begin{array}{c}\text { Sentez Gaz } \\
(\mathrm{g})\end{array}$ \\
\hline$<0,5 \mathrm{~cm}, 500^{\circ} \mathrm{C}$ & 100 & 25 & 30 & 45 \\
\hline $1-5 \mathrm{~cm}, 500^{\circ} \mathrm{C}$ & 100 & 16 & 35 & 49 \\
\hline $5-10 \mathrm{~cm}, 500^{\circ} \mathrm{C}$ & 100 & 26 & 34 & 40 \\
\hline$<0,5 \mathrm{~cm}, 750^{\circ} \mathrm{C}$ & 100 & 22 & 26 & 52 \\
\hline $1-5 \mathrm{~cm}, 750^{\circ} \mathrm{C}$ & 100 & 20 & 27 & 53 \\
\hline $5-10 \mathrm{~cm} 750^{\circ} \mathrm{C}$ & 100 & 22 & 25 & 53 \\
\hline
\end{tabular}

\section{SONUÇ}

Süt endüstrisi arıtma çamuru pirolizinde sıcaklık ve parçacık boyutu için optimum işletim şartlarının belirlenmesi ve proses verimi üzerinde yapılan bu çalışmaya göre, arıtma çamuru kekinde tanecik boyutu arttıkça 1sıl değerde düşüş görülmektedir. Tanecik boyutu ve sicaklığın elde edilen sentez gaz bileşimine etkisi incelendiğinde, sıcaklığın etkisinin daha belirgin olduğu anlaşılmaktadır. Her 
ne kadar parçacık boyutu sentez gaz oluşumunu etkilese de, yeterli sıcaklığı ulaşıldığında, parçacık boyutunun elde edilen gaz kompozisyonuna olan etkisinin sicaklığa nazaran daha az olduğu görülmüştür (Şekil 8). Yürütülen iki farklı sicaklıkta elde edilen sentez gazlar için elde edilen en yüksek 1 sıl değerler, $500^{\circ} \mathrm{C}$ için $1359 \mathrm{kcal} / \mathrm{m}^{3}$, $750^{\circ} \mathrm{C}$ için $4394 \mathrm{kcal} / \mathrm{m}^{3}$ olarak hesaplanmıştır. Bu sonuçla piroliz sıcaklığının ısıl değer üzerine olan etkisi net olarak gözlenmiştir.

$\mathrm{Bu}$ çalışmayla süt endüstrisi atıksu arıtma çamurunun önemli ölçüde ısıl değere sahip olduğu ve termal proseslere uygun bir atık olduğu ortaya konulmuştur. Enerjinin geri kazanımı ve atıklardan enerji eldesi her geçen gün önemini arttırmaktadır. Özellikle arıtma çamurlarının yönetimi konusunda termal yöntemlerin uygulanmasıyla, özellikle organik içeriği yüksek olan arıtma çamurları çevresel bir sorun olmaktan öte alternatif enerji kaynağı olarak kullanılabilecektir. Böylelikle çevresel bir sorunun çözümüyle birlikte ekonomik kazanç da sağlanmış olacaktır.

\section{TEŞEKKÜR}

$\mathrm{Bu}$ çalışma İstanbul Üniversitesi Bilimsel Araştırma Projeleri Koordinasyon Birimi Tarafindan Desteklenmiştir (Proje numarası: 26108).

\section{KAYNAKLAR}

1. Ridout A., Carrier M., Collard F.X., Görgens J., 2016. Energy Conversion Assessment of Vacuum, Slow and Fast Pyrolysis Processes for Low And High Ash Paper Waste Sludge, Energy Conversion and Management, 111: 103-114

2. Toraman Y., Topal H., 2003. Katı Atık ve Arıtma Çamurlarının Değerlendirilmesinde Alternatif Termal Teknolojiler ve Uygulamaları Gazi Üniversitesi Mühendislik Mimarlık Fakültesi Dergisi,18(1):19-33

3. Özcan H.K., Öngen A., Elmaslar Özbaş E., Sivri N., Pangaliyev Y., 2015. Atık Lastiklerden Termokimyasal Yöntemlerle Katı ve Sıvı Ürün Eldesi, 7. Ulusal Katı Atık
Yönetimi Kongresi, Gaziantep, Türkiye, 14-16 Ekim 2015.

4. Öngen A., 2011. Endüstriyel Atıklardan Termokimyasal İşlemlerle Sentez Gaz (Syngas) Üretimi, Doktora Tezi, İstanbul Üniversitesi Fen Bilimleri Enstitüsü.

5. Ganesapillai M., Manara, P., Zabaniotou A., 2016. Effect of Microwave Pretreatment on Pyrolysis of Crude Glycerol-Olive Kernel Alternative Fuels, Energy Conversion and Management 110: 287-295.

6. Chen W., Shi S., Zhang J., Chen M., Zhou, X., 2016. Co-pyrolysis of Waste Newspaper with High-Density Polyethylene: Synergistic Effect and Oil Characterization, Energy Conversion and Management, 112: 41-48.

7. Haydarya J., Susa D., Gelinger V., Cacho F. 2016. Pyrolysis of Automobile Shredder Residue in a Laboratory Scale Screw Type Reactor, Journal of Environmental Chemical Engineering, 4: 965-972

8. Pangaliyev Y., 2014. Ömrünü Tamamlamış Lastiklerden Piroliz/Gazlaştırma ile Değerlendirilebilir Ürün Eldesi, Master Tezi, Istanbul Universitesi Fen Bilimleri Enstitüsü.

9. Chhiti Y., Kemiha M., 2013. Thermal Conversion of Biomass, Pyrolysis and Gasification: A Review, The International Journal of Engineering And Science, 2 (3), 7585.

10. Tripathi M., Sahu J.N., Ganesan P., 2016. Effect of Process Parameters on Production Of Biochar From Biomass Waste Through Pyrolysis: A Review, Renewable and Sustainable Energy Reviews, 55: 467-481.

11. Basu, P., 2010. Biomass Gasification and Pyrolysis, Elsevier, ISBN: 978-0-12-374988-8

12. Aşı1k B.B., Katkat A.H., 2004. Gıda Sanayi Arıtma Tesisi Atığının (Arıtma Çamuru) Tarımsal Alanlarda Kullanım Olanakları Uludag Üniversitesi Ziraat Fakültesi Dergisi, 18(2): 59-71.

13. Gürtekin E., 2009. Ardışık Kesikli Reaktörde Süt Endüstrisi Atıksularının Biyolojik Arıtımı, Selçuk Üniversitesi Müh-Mim. Fakültesi Dergisi, 24(1): 1-6.

14. Han R., Zhao C., Liu J., Chen A., Wang H., 2015. Thermal Characterization and Syngas Production from the Pyrolysis of Biophysical 
Dried and Traditional Thermal Dried Sewage Sludge, Bioresource Technology, 198: 276282.

15. Omoriyekomwan J.E., Tahmasebi A., Yu J., 2016. Production of Phenol-rich Bio-oil During Catalytic Fixed-bed and Microwave Pyrolysis of Palm Kernel Shell, Bioresource Technology, 207: 188-196

16. Chen W., Shi S., Zhang J., Chen M., Zhou X., 2016. Co-pyrolysis of Waste Newspaper with High-Density Polyethylene: Synergistic Effect and Oil Characterization, Energy Conversion and Management 112: 41-48.

17. Bartocci P., D'Amico M., Moriconi N., Bidini G., Fantozzi F., 2015. Pyrolysis of Olive Stone for Energy Purposes, Energy Procedia, $\quad 82$ : 374-380.

18. Han R., Zhao C., Liu C., Chen A., Wang H., 2015. Thermal Characterization and Syngas Production from the Pyrolysis of Biophysical Dried and Traditional Thermal Dried Sewage Sludge, Bioresource Technology, 198: 276282.

19. Liu G., Song H., Wu J., 2015. Thermogravimetric Study and Kinetic Analysis of Dried Industrial Sludge Pyrolysis, Waste Management, 41: 128-133.

20. Yuan H., Lu T., Huang H., Zhao D., Kobayashi N., Chen Y., 2015. Influence of Pyrolysis Temperature on Physical and Chemical Properties of Biochar made from Sewage Sludge, Journal of Analytical and Applied Pyrolysis, 112: 284-289.

21. SM 2540 E, 1998. Standard Methods for the Examination of Water and Wastewater $20^{\text {th }}$ Edition, Franson.M.H., American Public Health Association, ISBN:0-87553-235-7.

22. SM 2540 B, 1998. Standard Methods for the Examination of Water and Wastewater $20^{\mathrm{tl}}$ Edition, Franson.M.H., American Public Health Association, ISBN:0-87553-235-7.

23. Waldheim L, Nilsson T., 2001. Heating Valus of Gases From Biomass Gasification. Report prepared for: IEA Bioenergy Agreement, Task 20 - Thermal Gasification of Biomass, Report no: TPS-01/16, TPS Termiska Processer AB. 
